\title{
Ambiente de Aprendizagem Ubíqua para Auxiliar o Estudo de Botânica em Atividades de Aula de Campo
}

\author{
Karoene D. S. Mendonça ${ }^{1}$, João V. A. de Oliveira ${ }^{1}$, Átila R. Lopes ${ }^{1,2}$, Rosana T. V. Braga ${ }^{2}$ \\ ${ }^{1}$ Universidade Estadual do Piauí (UESPI) - Parnaíba -PI - Brasil \\ ${ }^{2}$ Instituto de Ciências Matemáticas e de Computação (ICMC/USP) - Universidade de São Paulo \\ Caixa Postal 13.566-590 - São Carlos - SP - Brasil \\ \{karoene.d.s.mendonca, joaoaraujo.367\}@gmail.com, atilarlopes\{@usp.br, \\ egmail.com\}, rtvb@icmc.usp.br
}

\begin{abstract}
This article is the result of a developing research project, which proposes the construction of a ubiquitous learning environment to assist the teaching-learning process of botany, serving as a didactic resource for activities carried out in field lessons. In this way, the article summarizes the most important aspects of the project and its current phase of development.
\end{abstract}

Resumo. Este artigo é fruto de um projeto de pesquisa em desenvolvimento, que tem como proposta a construção de um ambiente de aprendizagem ubíqua para auxiliar o processo de ensino-aprendizagem de botânica, servindo como um recurso didático para atividades realizadas em aulas de campo. Desta forma, o artigo resume os aspectos mais importantes do projeto e sua fase atual de desenvolvimento.

\section{Introdução}

Aula de campo é uma modalidade de ensino que ajuda o aluno a ampliar suas habilidades de observação, descoberta e assimilação do conteúdo visto no ambiente natural do estudo [Pyke 2015]. No entanto, a quantidade de recursos didáticos necessários em algumas atividades de campo, aliado à cansativa tarefa do professor em acompanhar individualmente vários alunos dispersos no campo podem comprometer o seu rendimento [Roslin et al. 2013].

Diante disso, a proposta deste trabalho consiste em contribuir para o processo de ensino e aprendizagem de botânica (estudo das plantas), fornecendo apoio para execução de aulas de campo por meio do desenvolvimento de uma aplicação u-learning.

\section{Aula de Campo}

O modelo de aula de campo favorece a aprendizagem, pois permite ao aluno assimilar melhor a teoria com a realidade prática do assunto, uma vez que a aprendizagem ocorre no ambiente natural do objeto de estudo [Shakil, Faizi e Hafeez 2011].

Porém, a literatura aponta algumas dificuldades neste modelo de aula, tais como: acompanhamento individual de muitos alunos, ao mesmo tempo; aulas com muitas atividades diferentes (análise, observação, coleta e registro de informações), assim como atividades que necessitam de uma variedade de recursos didáticos, tais como: GPS, bússola, câmera digital, gravador de áudio, caderno de anotações, etc. [Roslin et al. 2013] e [Shakil, Faizi e Hafeez 2011]. 
VII Congresso Brasileiro de Informática na Educação (CBIE 2018)

Anais do XXIX Simpósio Brasileiro de Informática na Educação (SBIE 2018)

\section{Aprendizagem Ubíqua}

Aprendizagem ubíqua pode ser definida como a utilização de dispositivos e tecnologias móveis, sensores e mecanismos de localização, os quais levam em consideração o contexto de cada estudante, objetivando auxiliar no processo educacional.

Contexto, de acordo com [Dey 2001], é definido como "qualquer informação que pode ser utilizada para caracterizar a situação de entidades (pessoa, lugar ou objeto) que são consideradas relevantes para a interação entre o usuário e a aplicação".

\section{Descrição da Proposta}

O ambiente está sendo desenvolvido com base em uma arquitetura de referência orientada a serviços (SOA) e é composto por duas camadas (cliente e servidor). A camada cliente consiste em uma interface para dispositivos móveis, equipados com GPS e com acesso à internet. Já a camada do servidor é composta por um conjunto de serviços web, em especial os serviços baseados na localização (LBS), que fornecem as funcionalidades para a aplicação cliente.

Os principais serviços web para o ambiente de aprendizagem ubíqua são os seguintes: (i) serviços de contexto: que tratam das questões relacionadas à aquisição das coordenadas de localização GPS e outras funções como, por exemplo, cálculo da distância e verificação de proximidade entre dois pontos; e (ii) serviços de autoria: que permite ao usuário criar conteúdos didáticos (texto) e também criar atividades de aprendizagem utilizando os conteúdos e os LBS para prover serviços de aprendizagem sensíveis ao contexto de localização do usuário.

\section{Cenário da Atividade de Campo com o Aplicativo}

Para facilitar a compreensão sobre o uso da ferramenta em atividades de campo foi criado um cenário de aplicação, validado informalmente pela análise dos cenários presentes no estado da arte. No entanto, ainda será feita uma pesquisa junto a especialistas da área (professores de botânica) para formalizar, cientificamente, a validação do cenário, apresentado a seguir.

Para criar a atividade, o professor captura a localização das plantas, no campo de estudo, utilizando o GPS do celular. Em seguida, ela cria todos os conteúdos de aprendizagem e associa às respectivas plantas (coordenadas capturadas), sendo dois conteúdos distintos (Certo e Errado) associadas a cada planta. O conteúdo é uma descrição das características das plantas que serão estudadas na atividade de campo.O conteúdo "Certo" confirma o acerto e exibe a descrição da próxima planta que o aluno deve procurar. Enquanto o conteúdo "Errado" indica o erro do aluno e apresenta características adicionais para ajudá-lo a encontrar a planta correta.

A atividade começa quando o professor fornece as características da primeira planta a ser encontrada no campo de estudo (jardim botânico). Os alunos procuram a planta com as características fornecidas, se aproximam da que acham ser a correta e confirmam a resposta no aplicativo do celular, que envia a localização do aluno para o servidor web que, por sua vez, verifica se o aluno está próximo da planta correta e exibe 
VII Congresso Brasileiro de Informática na Educação (CBIE 2018)

Anais do XXIX Simpósio Brasileiro de Informática na Educação (SBIE 2018)

um dos conteúdos associados à planta ("Certo" ou "Errado"). A atividade termina quando todas as plantas tiverem sido encontradas corretamente.

\section{Desenvolvimento do Ambiente U-learning}

Este artigo é referente a um projeto de pesquisa que está sendo desenvolvido, de acordo com as seguintes etapas metodológicas: pesquisas bibliográficas, análise e especificações do ambiente, implementação e validação da proposta.

Atualmente, o projeto está executando a etapa de implementação, onde já foi construído um protótipo inicial da aplicação cliente (framework Ionic) e um servidor web (PHP), para verificar se as seguintes funcionalidades foram implementadas corretamente: cadastro, login, autoria de conteúdo e captura do contexto (localização). Os resultados dos testes preliminares foram satisfatórios, uma vez que, foi possível identificar e corrigir os erros lógicos presentes no código-fonte da aplicação cliente e dos serviços web. Ainda serão feitos mais testes funcionais, assim como testes de usabilidade, desempenho e interface, com as próximas versões do protótipo.

\section{Considerações Finais e Trabalhos Futuros}

Este trabalho apresentou uma proposta voltada para o desenvolvimento de um aplicativo u-learning sensível ao contexto, utilizando serviços baseados na localização, para servir como recurso didático no ensino-aprendizagem de botânica, em atividades de campo.

O trabalho está em fase de desenvolvimento, com alguns resultados parciais obtidos nas etapas iniciais do projeto, como os requisitos levantados e definidos, a caracterização do cenário de aplicação e a arquitetura do ambiente.

Como trabalhos futuros, pretende-se concluir a etapa de desenvolvimento e aplicar novos testes funcionais e realizar também o teste de validação para verificar o comportamento do sistema no ambiente real de aplicação, e constatar se os objetivos desta pesquisa foram alcançados.

\section{Referências}

DEY, A. (2001). Understanding and Using Context. Personal and Ubiquitous Computing, vol.5, no. 1, pages 4-7.

PYKE, K. L. (2015). Effects of field trips on alternative students' knowledge skills, attitudes, and relationships. Thesis submitted in partial fulfillment of the requirements for the degree of Master of Arts in Royal Roads University. Disponível em: https://viurrspace.ca/handle/10170/823.

ROSLIN, Ma Anya Yasmin A. et al. Social impact of ecotourism on the behavior of students on educational field trips to Makiling Botanic Gardens in the University of the Philippines Los Baños. USM R\&D Journal, v. 17, n. 1, p. 71-80, 2009.

SHAKIL A., FAIZI W. E HAFEEZ S. The need and importance of field trips at higher level in karachi, pakistan. In: International Journal of Academic Research in Business and Social Sciences, June, Vol. 2, No. 1, 2011. 